ТРЕЩЕНКОВ Евгений Юрьевич - кандидат исторических наук, доцент кафедры международных отношений на постсоветском пространстве Санкт-Петербургского государственного университета (191124, Россия, г. Санкт-Петербург, ул. Смольного, 1/3, под.8; e.treschenkov@spbu.ru)

\title{
СТРЕССОУСТОЙЧИВОСТЬ В СОВРЕМЕННЫХ ДИСКУРСАХ УПРАВЛЕНИЯ
}

\begin{abstract}
Аннотация. Понятие стрессоустойчивости (resilience) прочно вошло в современный дискурс ряда международных организаций и государств. В статье проведен анализ артикуляции стрессоустойчивости в дискурсах трех взаимосвязанных уровней - глобального управления (на примере ООН), наднационального регионального управления (на примере $E C$ ) и национального управления (на примере Великобритании и США). Автор делает выводы как относительно специфики использования понятия на разных уровнях, так и относительно причин его распространения в дискурсах управления и безопасности в последнее десятилетие. Отдельное внимание уделяется релевантности дискурса стрессоустойчивости российской практике.
\end{abstract}

Ключевые слова: управление, стрессоустойчивость, неолиберализм, новое управленчество

Remember that resilience is a skill, like riding a bike. The more you practice, the better you'll be ${ }^{1}$. U.S. Department of State

$\mathrm{B}^{\mathrm{c}}$ современных дискурсах национального и глобального управления все чаще можно наблюдать присутствие такого понятия, как стрессоустойчивость (resilience) ${ }^{2}$. В системе Организации Объединенных Наций оно неоднократно упоминается в Целях устойчивого развития (Sustainable Development Goals) ${ }^{3}$, красной нитью пронизывает тексты Сендайской рамочной программы по снижению риска стихийных бедствий, используется в девизе Программы развития ООН (Empowered lives. Resilient nations). Углубленные разработки практического применения стрессоустойчивости ведет Организация экономического сотрудничества и развития 4 . Европейский союз в 2016 г. сделал понятие ядром своей новой Глобальной стратегии внешней политики и безопасности ${ }^{5}$. В современном дискурсе Северо-Атлантического альянса стрессоустойчивость используется для обозначения способности организации противостоять гибридным угрозам 6 . Более 4 тыс. материалов на правительственном интернет-портале Великобритании (www.gov.uk) содержат упоминание стрессоустойчивости.

Академическое сообщество также проявляет большой интерес к понятию, дискутируя как о степени его новизны, так и о способности заменить в управленческом дискурсе такие концепции, как, например, устойчивое развитие (sustainable development) [Walker, Cooper 2011]. Существуют целые эпистемные сообщества по стрессоустойчивости (например, Resilience Alliance), а также

\footnotetext{
${ }^{1}$ What is resilience? Доступ: https://www.state.gov/m/med/dsmp/c44950.htm

2 Такой перевод на русский язык представляется достаточно хорошо отражающим суть понятия, и он широко применяется российскими исследователями. См., напр., Романова Т.А. 2017. Категория «стрессоустойчивость» в Европейском союзе. - Современная Европа. № 4. С. 17-28.

3 UN Resolution «Transforming our world: the 2030 Agenda for Sustainable Development». 21 October 2015. URL: http://www.un.org/ga/search/view_doc.asp?symbol=A/RES/70/1\&Lang=E (accessed 15.07.2018).

4 OECD. Guidelines for resilience systems analysis. OECD Publishing. 2014.

5 Shared Vision, Common Action: A Stronger Europe. A Global Strategy for the European Union's Foreign and Security Policy. Brussels. 28 June 2016. URL: https://europa.eu/globalstrategy/en/shared-visioncommon-action-stronger-europe (accessed 15.07.2018).

6 Resilience: a core element of collective defense. URL: https://www.nato.int/docu/review/2016/Alsoin-2016/nato-defence-cyber-resilience/EN/index.htm (accessed 15.07.2018).
} 
исследовательские и образовательные программы (Stockholm Resilience Centre). Неправительственные организации запускают программы укрепления стрессоустойчивости городов и местных сообществ ${ }^{1}$.

В предлагаемой статье предпринята попытка выявить причины и контекст активного проникновения понятия стрессоустойчивости в дискурсы управления на разных уровнях (глобальном, региональном и национальном). В связи с этим представляется целесообразным ответить на 3 вопроса:

1) как рост популярности стрессоустойчивости согласуется с современными глобальными и региональными тенденциями, и о чем сигнализирует нам активное проникновение стрессоустойчивости в управленческий дискурс;

2) в чем специфика артикуляции понятия на разных уровнях - глобальном, региональном, национальном;

3) насколько указанная тема является релевантной российскому опыту?

Для достижения цели исследования и ответов на поставленные вопросы предлагается, во-первых, кратко охарактеризовать эволюцию понятия в академическом дискурсе, а также причины его проникновения в дискурсы управления и безопасности, после чего на примере трех взаимосвязанных кейсов $(\mathrm{OOH}, \mathrm{EC}$, Великобритания и США) определить специфику присутствия понятия стрессоустойчивости в дискурсах управления каждого из уровней. При этом следует оговориться, что предметом изучения здесь выступают только государственные и наднациональные дискурсы управления. Микроуровень (корпорации, малый и средний бизнес, индивиды), где понятие стрессоустойчивости также используется, находится за скобками исследования.

\section{Появление и содержание понятия стрессоустойчивости}

Стрессоустойчивость как академическое понятие оформилось в рамках экологии в 1970-е гг. Она использовалась для описания способности экологических систем выдерживать воздействие шоков, восстанавливаться и адаптироваться к изменяющимся условиям [Holling 1973: 17-18]. С наступлением условий «общества риска» системный подход обеспечил привлекательность понятия стрессоустойчивости для анализа разнообразных социальных и экономических процессов в условиях глобализации. Постепенно через экспертную активность из сферы науки понятие стрессоустойчивости было перенесено в сферу управления. В этом процессе стрессоустойчивость потеряла академическую целостность, превратившись в «пограничное понятие», используемое бюрократами в коммуникативных целях [Brand, Jax 2007]. Стрессоустойчивость стала реакцией управляющих на разнообразные и труднопредсказуемые вызовы безопасности.

Особое распространение стрессоустойчивость получила в дискурсах безопасности англосаксонских стран (США, Великобритания). Это было вызвано, помимо прочего, созвучностью базовых положений концепции неолиберальной парадигме. Речь идет о внимании управляющих к параметрам управляемых ими систем, а также к формированию непрямых способов контроля за их развитием и использованием. Не случайно в академическом сообществе сложилась тенденция изучения стрессоустойчивости через призму идеи М. Фуко о формировании «нового управленчества» ${ }^{2}$. Феномен «нового управленчества» обозначает постепенный сдвиг в восприятии управляющими сути управления в сторону внимания к характеристикам управляемых и непрямым способам

\footnotetext{
1 Например, программа «100 стрессоустойчивых городов» (100 Resilient Cities, http:// www.100resilientcities.org/), реализуемая фондом Рокфеллера.

2 В русскоязычной литературе встречаются разные переводы понятия governmentality. Из набора имеющихся вариантов (правительственность, властоментальность) термин «управленчество» представляется в наилучшей степени передающим смысл.
} 
манипулирования ими. Изменение практик управления связано с развитием либерализма, рассматриваемого как метод и принцип рационализации управления. Правление перестает быть самоцелью, а государственные интересы более не являются оправданием возрастания роли государства и его регулирующих функций [Фуко 2010: 406]. При этом цель управленчества, согласно Фуко, заключается во внедрении таких механизмов безопасности, которые наиболее соответствуют течению естественных феноменов человеческой деятельности (например, экономических процессов). Свобода становится необходимым элементом управления [Фуко 2011: 455].

Тем не менее современные исследователи подчеркивают неоднозначность взаимосвязи стрессоустойчивости и неолиберализма. Одни указывают на то, что стрессоустойчивость используется капитализмом как «контрреволюционное» понятие. Перенос акцента на стрессоустойчивость на локальном уровне не сопровождается передачей реальной власти гражданам, в то время как государство снимает с себя часть ответственности за безопасность своих подопечных. Другие все же признают наличие у стрессоустойчивости трансформационного потенциала для преодоления издержек капитализма [Павлова, Гудалов, Коцур 2017]. Как бы там ни было, очевидно, что понятие стрессоустойчивости получило наибольшее распространение именно в тех практиках управления и безопасности, которые связаны с доминированием западных институтов.

\section{Глобальный уровень: ООН}

Система ООН, в особенности те ее институты, которые призваны содействовать устойчивому развитию стран глобального Юга, формировались под большим идеологическим и экспертным влиянием США и стран Западной Европы. Как известно, группа Всемирного банка, Всемирная торговая организация, Международный валютный фонд подвергаются серьезной критике как институты, продвигающие неолиберальные рецепты без учета локальной специфики, а также укрепляющие зависимость развивающихся стран от развитых [Стиглиц 2003].

На современном этапе в системе ООН рост использования понятия стрессоустойчивости произошел в результате осмысления ситуации с международной помощью странам Восточной Африки, пострадавшим в 2011 г. от беспрецедентной засухи и, как следствие, массового голода. Основная идея заключалась в том, что международное сообщество должно не просто предоставлять гуманитарную помощь, но способствовать формированию в странах-реципиентах внутренних ресурсов для самостоятельного преодоления кризисов. Это позволит, несмотря на наступление очередного кризиса, сохранить достигнутый с международной помощью прогресс. В ООН понятие стрессоустойчивости сохранило свое первоначальное отношение к экологии. Наибольшее распространение в этом ключе оно приобрело в концептуальных документах Бюро ООН по снижению риска стихийных бедствий. Параллельно в рамках Программы развития $\mathrm{OOH}$, а также дискурса Всемирного банка и Международного валютного фонда появляются такие измерения, как социально-экономическая, микро- и макроэкономическая, финансовая стрессоустойчивость. Издаются отдельные развернутые руководства, содержащие методологию измерения стрессоустойчивости национальной экономики, а также рекомендации по ее укреплению [Hallegatte 2014].

Появление и распространение стрессоустойчивости в дискурсе глобального управления прежде всего сигнализирует о неудовлетворенности международного сообщества эффективностью существующего инструментария устойчивого развития. Последнее исходит из идеи установления такой модели раз- 
вития человечества, которая минимизировала бы возникновение рисков и угроз. Стрессоустойчивость предлагает взглянуть на риск как неотъемлемую часть рационально принимаемых человеком решений. Риск неизбежен, следовательно, акцент следует делать не на его предотвращении, а на укреплении ресурсов для преодоления его последствий. Для этого часть ответственности разумно оставить за странами - реципиентами помощи развитию, поскольку, столкнувшись с кризисом, они должны быть способными на самостоятельные, автономные действия. Вместе с тем устойчивое развитие и стрессоустойчивость в дискурсе ООН не противопоставляются друг другу ${ }^{1}$. Категория стрессоустойчивости, хоть и внесла в теорию и практику устойчивого развития дополнительное измерение, не затронула принципиальным образом суть существующего инструментария.

\section{Региональный уровень: Европейский союз}

Первым документом ЕС, где стрессоустойчивость была обозначена в качестве ключевого понятия, стала принятая в ноябре 2011 г. программа поддержки стран Африканского Рога, пострадавших от засухи ${ }^{2}$. Таким образом, возникновение системного интереса к категории стрессоустойчивости совпало в Евросоюзе с ее актуализацией в дискурсе глобального управления ООН. Следует отметить, что системе ООН отводится ключевое место в видении европейцами настоящего и будущего мироустройства ${ }^{3}$. Олицетворяемые ею принципы многосторонности и верховенства права являются основой самой европейской интеграционной модели. Европейский союз и его страны-члены в совокупности являются крупнейшим донором международной помощи развитию. На них также приходится более $30 \%$ ассигнований в бюджет $\mathrm{OOH}^{4}$. Дискурсы ООН и Европейского союза в том, что касается проблематики международной помощи развитию и глобального управления, теснейшим образом взаимосвязаны. Не случайно первоначально сформулированный подход Евросоюза к стрессоустойчивости в целом не выходил за рамки дискурса $\mathrm{OOH}^{5}$.

Ситуация стала меняться в связи с совокупностью наложившихся друг на друга вызовов, с которыми столкнулась европейская интеграционная модель в последующие годы. Здесь следует упомянуть миграционный кризис 2015 г., российско-украинский конфликт и фактический разрыв отношений с Россией в 2013-2014 гг, решение правительства консерваторов о проведении референдума о выходе Великобритании из ЕС и др. Теперь речь шла уже не только о стрессоустойчивости развивающихся стран и даже не о стрессоустойчивости ближайших соседей ЕС, но и о будущем самого европейского проекта. Из внешней категории стрессоустойчивость постепенно стала для Евросоюза внутренней. Именно такая многоуровневость понятия стрессоустойчивости была зафиксирована в принятой в июне 2016 г. Глобальной стратегии внеш-

\footnotetext{
1 Secretary-General's message on Human Rights Day. 10 December 2016. URL: https://www.un.org/ $\mathrm{sg} / \mathrm{en} / \mathrm{content} / \mathrm{sg} / \mathrm{statement} / 2016-12-10 /$ secretary-generals-message-human-rights-day-scroll-down-french (accessed 15.07.2018).

2 European Commission Staff Working Document «SHARE: Supporting Horn of Africa Resilience». SWD(2012) 102 final. Brussels. 11 April 2012.

3 Consolidated version of the Treaty on European Union. - Official Journal of the European Union. 26 October 2012.

4 The European Union at the United Nations, fact sheet. Bruxelles. 14.09.2017. URL: https://eeas.europa. eu/headquarters/headquarters-homepage/9875/european-union-united-nations_en (accessed 15.07.2018).

5 Council conclusions on EU approach to resilience. $3241^{\text {st }}$ Foreign Affairs Council meeting. 28 May 2013. Brussels. URL: http://www.consilium.europa.eu/uedocs/cms_data/docs/pressdata/EN/foraff/137319. pdf (accessed 15.07.2018); Communication from the Commission to the European Parliament and the Council «The EU Approach to Resilience: Learning From Food Security Crises». COM(2012) 586 final. Brussels. 3 October 2012.
} 
ней политики и безопасности ЕС ${ }^{1}$. Стабилизация и помощь в формировании стрессоустойчивости обществ и государств в соседних с Евросоюзом регионах стали важным условием обеспечения стрессоустойчивости самой европейской модели.

\section{Национальный уровень: Великобритания и Соединенные Штаты}

Англосаксонское происхождение понятия стрессоустойчивости, а также его содержательная связь с неолиберальными практиками управления делают неизбежным обращение к артикуляции этого понятия в дискурсах управления стран Запада. Понятие стрессоустойчивости занимает ключевое место в дискурсах национальной безопасности Великобритании и США. Сходства объясняются как доминирующей в обоих случаях неолиберальной парадигмой, так и многочисленными и разветвленными двусторонними отношениями. Вслед за ООН стрессоустойчивость присутствует в повестке международной помощи развитию Великобритании и США, однако этой сферой все не ограничивается.

Здесь стрессоустойчивость раньше, чем в ООН или ЕС, была интегрирована в официальный дискурс безопасности. И в США, и в Великобритании доминирует представление о том, что в современном мире невозможно предсказать и предотвратить все возможные угрозы и риски. По этой причине акцент следует делать на подготовленности к наступлению кризисной ситуации на всех уровнях управления. Подготовленность заключается в укреплении стрессоустойчивости.

В Национальной стратегии внутренней безопасности США 2007 г. говорится о двух измерениях стрессоустойчивости - структурном и операционном. Под первым понимается обеспечение стрессоустойчивости на всех уровнях и всеми элементами системы - от федерального правительства до каждого гражданина. Под операционной стрессоустойчивостью - обеспечение должного уровня координации, планирования и коммуникации между всеми акторами, представляющими разные уровни системы. При этом неолиберализм политики стрессоустойчивости определяется характером политической и экономической системы Соединенных Штатов. Как справедливо отмечают авторы Стратегии, $85 \%$ критически важных объектов инфраструктуры находятся в частной собственности ${ }^{2}$. В такой ситуации вряд ли корректно будет говорить об умышленном перекладывании правительством ответственности на граждан, бизнес или местные власти. Без их вовлечения укрепление стрессоустойчивости экономики и государства оказывается попросту невозможным.

Соответственно, одним из наиболее распространенных инструментов осуществления координирующей роли государственного аппарата в процессе укрепления стрессоустойчивости и в США, и в Великобритании являются различного рода руководства, программы и справочные материалы. Они, как правило, содержат рекомендации для соответствующего уровня системы (например, для академического сообщества $3{ }^{3}$ или для бизнеса $\left.{ }^{4}\right)$ по интеграции его самостоятельных усилий в общую канву, а также примеры соответствующего успешного опыта.

\footnotetext{
${ }^{1}$ Shared Vision, Common Action: A Stronger Europe. A Global Strategy for the European Union's Foreign and Security Policy. 28 June 2016. URL: https://europa.eu/globalstrategy/en/shared-vision-common-actionstronger-europe (accessed 15.07.2018).

2 The National Strategy for Homeland Security. October 2007. URL: https://www.dhs.gov/nationalstrategy-homeland-security-october-2007 (accessed 15.07.2018).

3 Campus Resilience Program Resource Library. URL: https://www.dhs.gov/campus-resilience-programresource-library (accessed 15.07.2018).

4 How resilient is your business to disaster. 1 January 2006. URL: https://www.gov.uk/government/ publications/how-resilient-is-your-business-to-disaster (accessed 15.07.2018).
} 
Сферы использования категории стрессоустойчивости в США и Великобритании крайне разнообразны и не ограничиваются только тематикой национальной безопасности и международной помощи развитию. При этом стрессоустойчивость присутствует не только в повестке центральных властей, но и на следующих уровнях управления. Так, в Шотландии ежегодно проводится неделя стрессоустойчивости, в ходе которой каждому жителю предлагается задуматься над его/ее подготовленностью к широкому спектру чрезвычайных ситуаций - от резкого ухудшения погоды до безопасности в Интернете 1 . Действует специальный фонд (Community Capacity and Resilience Fund), основной задачей которого является помощь третьему сектору в установлении рабочих контактов с местными сообществами для организации помощи социальным группам, уязвимым перед лицом чрезвычайных ситуаций.

Если обратиться к уровню локальных властей, то при окружном совете Глазгосити функционирует отдельная структура, обеспечивающая координацию всех служб региона в случае чрезвычайных ситуаций (Glasgow City Council Resilience Unit). В ее же полномочия входит разработка различных планов и руководств. У города, участвующего в проекте фонда Рокфеллера «100 стрессоустойчивых городов», есть собственная стратегия в области стрессоустойчивости ${ }^{2}$.

Аналогично и в Соединенных Штатах философия стрессоустойчивости близка как отдельным штатам, так и городам. Губернатор штата Вашингтон прямо говорит о том, что «вопрос заключается не в том, случится ли масштабное землетрясение, а в том, насколько хорошо мы будем к нему готовы» ${ }^{3}$. В свою очередь, один из крупнейших городов штата - Сиэтл - совместно с частным сектором разрабатывает Стратегию стрессоустойчивости (Resilience Strategy), призванную стать основой формирования стрессоустойчивости и распространения «стрессоустойчивого мышления» (resilience thinking) ${ }^{4}$.

\section{Релевантность российским практикам}

В российском дискурсе управления, находящемся под сильным воздействием идей примата государственных интересов над частными и патернализма, мало места для распространения неолиберальной версии стрессоустойчивости. К тому же последняя предполагает не только автономию граждан и бизнеса, но и их способность и желание нести свою долю ответственности. В российской практике коммуникации государственного аппарата с управляемыми отсутствует потребность в терминологии стрессоустойчивости. Впрочем, концепция стрессоустойчивости, будучи освобожденной от неолиберальных идеологических наслоений, может применяться к анализу безопасности экономики или общественных отношений в России. Можно, например, рассматривать коррупционные практики в качестве элемента стрессоустойчивости системы [Павлова 2017; Дарден 2009]. В этом ключе инструментарий концепции стрессоустойчивости будет обладать определенной познавательной ценностью.

Пока же стрессоустойчивость (resilience) практически отсутствует в качестве академического термина в России. Это сопровождается и отсутствием российской активности в процессах артикуляции стрессоустойчивости в дискурсе глобального управления. До сих пор нет единого русскоязычного термина для

\footnotetext{
${ }^{1}$ Resilience Week. 5 November 2017. URL: https://beta.gov.scot/news/resilience-week/ (accessed15.07.2018).

2 Our Resilient Glasgow. ACity Strategy. URL:https://www.glasgow.gov.uk/CHttpHandler.ashx?id=35134\&p=0 (accessed 15.07.2018).

3 Inslee launches new Resilient Washington subcabinet in preparation for Big One. November 4, 2016. URL: https://www.governor.wa.gov/news-media/inslee-launches-new-resilient-washington-subcabinet-preparationbig-one (accessed 15.07.2018).

4 Resilient Seattle. URL: http://www.seattle.gov/resilience (accessed 15.07.2018).
} 
обозначения понятия resilience. В Сендайской рамочной программе ООН по снижению риска бедствий resilience переводится на русский язык как «потенциал противодействия»1. В русскоязычном варианте резолюции Генеральной Ассамблеи, посвященной целям глобального развития, resilience переводится и как «жизнестойкость», и как «стойкость», и как «устойчивость» 2 . Это особенно странно с учетом того, что в англоязычных версиях соответствующих концептуальных документов ООН resilience употребляется как термин, имеющий более или менее консенсусное базовое значение.

Перемещение категории стрессоустойчивости из экологии в дискурсы управления и безопасности происходило в условиях доминирования неолиберальной парадигмы. Стрессоустойчивость оказалась особенно привлекательной для бюрократии государств, где либеральная политика приспосабливалась к конкуренции со стороны идей государства всеобщего благосостояния. Аналогично и международные институты (Всемирный банк, Программа развития ООН и др.), предлагая рецепты укрепления стрессоустойчивости странам - реципиентам международной помощи развитию, исходят из неолиберальной логики. В дискурсе глобального управления появление понятия стрессоустойчивости стало отражением растерянности международного сообщества по поводу трудно предсказуемых и разнообразных вызовов и угроз. При этом оно не заменило, а дополнило терминологию устойчивого развития. Россия, поставившая одной из своих задач формирование альтернатив доминированию западных подходов к глобальному управлению (в рамках $G 20$, БРИКС), тем не менее, слабо представлена в международной экспертизе, оказывающей принципиальное влияние на распространение в дискурсе глобального управления таких категорий, как стрессоустойчивость.

Исследование выполнено за счет гранта Российского научного фонда (проект № 17-18-01110).

\section{Список литературы}

Дарден К. 2009. Целостность коррумпированных государств: взяточничество как неформальный институт управления. - Прогнозис. № 2(18). С. 109-134.

Павлова Е.Б. 2017. «Стрессоустойчивость» в терминах Антонио Грамши: коррупция и здравый смысл. - Диалектика империи: революция vs преемственность. XI Конвент РАМИ. Москва. 28-29 сентября. Доступ: http://www.risa.ru/ru/ sections/cektsii-viii-konventa-rami/37-xi-sections/354-5-2 (проверено 15.07.2018).

Павлова Е., Гудалов Н., Коцур Г. 2017. «Стрессоустойчивость»: новое слово в международных отношениях или вариация на неолиберальную тему? - Вестник Московского университета. Сер. 25. Международные отношения и мировая политика. Т. 9. № 2. С. 170-182.

Стиглиц Дж. 2003. Глобализация: тревожные тенденции (пер. с англ. Г.Г. Пирогова). М.: Национальный общественно-научный фонд. 304 с.

Фуко М. 2010. Рождение биополитики (пер. с фр. А.В. Дьякова). СПб: Наука. $448 \mathrm{c.}$

Фуко М. 2011. Безопасность, территория, население (пер. с фр. В.Ю. Быстрова, Н.В. Суслова, А.В. Шестакова). СПб: Наука. 544 с.

\footnotetext{
1 Резолюция «Сендайская рамочная программа по снижению риска бедствий на 2015-2030 годы». Принята Генеральной Ассамблеей 03.06.2015. Доступ: https://www.preventionweb.net/files/resolutions/ N1516719.pdf (проверено 15.07.2018).

2 Резолюция «Преобразование нашего мира: Повестка дня в области устойчивого развития на период до 2030 года». Принята Генеральной Ассамблеей ООН. 25.09.2015. Доступ: http://www.un.org/ ga/search/view_doc.asp?symbol=A/RES/70/1\&Lang=R (проверено 15.07.2018).
} 
Brand F.S., Jax K. 2007. Focusing the Meaning(s) of Resilience: Resilience as a Descriptive Concept and a Boundary Object. - Ecology and Society. Vol. 12. No. 1.

Hallegatte S. 2014. Economic Resilience Definition and Measurement. - The World Bank Policy Research Working Paper. Доступ: http://documents.worldbank.org/ curated/en/350411468149663792/pdf/WPS6852.pdf (accessed 15.07.2018).

Holling C.S. 1973. Resilience and Stability of Ecological Systems. - Annual Review of Ecology and Systematics. Vol. 4. P. 1-23.

Walker J., Cooper M. 2011. Genealogies of Resilience: From Systems Ecology to the Political Economy of Crisis Adaptation. - Security Dialogue. Vol. 42. No. 2. P. 143-160.

TRESHCHENKOV Evgeniy Yur'evich, Cand.Sci. (Hist.), Associate Professor of the St.-Petersburg State University (entr.8, 1/3 Smolnogo Str, St.-Petersburg, Russia, 191060; e.treschenkov@spbu.ru)

\title{
RESILIENCE IN CONTEMPORARY GOVERNANCE DISCOURSES
}

\begin{abstract}
The notion of resilience has become firmly embedded in the contemporary discourse of a number of international organizations and states. In the UN system, resilience supplemented a glossary of sustainable development. In the UK, USA, France and other countries, it is actively used by national bureaucracies in security sphere. This article analyzes the articulation of this notion in the discourses of three interrelated levels - global governance (exemplified by the United Nations), supranational regional governance (EU) and national governance (United Kingdom and United States). The author draws conclusions concerning the specifics of the articulation of the concept at different levels, and about the reasons for its dissemination in the discourses of governance and security in the last decade. The article pays special attention to the relevance of the discourse of resilience to Russian practice.
\end{abstract}

Keywords: governance, resilience, neoliberalism, new governmentality 